\title{
Cardiovascular Burden of COVID-19 and the Post-Covid Era
}

\author{
Samuel D. Moscavitch, $1^{*}$ (®) Jefferson L. Vieira, ${ }^{2 *}$ Peter Libby \\ Division of Cardiovascular Medicine, Department of Medicine, Brigham and Women's Hospital, Harvard Medical School, ${ }^{1}$ Boston, MA - USA \\ Hospital de Messejana Dr. Carlos Alberto Studart Gomes, ${ }^{2}$ Fortaleza, CE - Brazil \\ *Both authors contributed equally to this work
}

Coronavirus disease 2019, or COVID-19, rapidly became pandemic in 2020, causing hundreds of million cases and more than 2 million related deaths. ${ }^{1}$ This scourge has affected a wide range of people, from children to older adults, from healthy to high-risk individuals. Since December 2019, when the first cases of a virulent pneumonia of unknown etiology emerged in Wuhan, China, COVID-19 has not only become a major global health threat but has stretched health care systems and providers to the limits worldwide. ${ }^{2}$

Infection with severe acute respiratory syndrome coronavirus 2 (SARS-CoV-2) has a variable clinical presentation, encompassing a wide range of symptoms similar to those of many infectious conditions, including fever, cough, and general malaise, now well known to most physicians worldwide. ${ }^{3,4}$ With disease progression, severe cases of COVID-19 can develop an acute lung injury with diffuse alveolar damage, producing the well-known bilateral infiltrates or ground glass opacities on chest x-ray or computed tomographic images. ${ }^{5-7}$ Although most cases are mild, patients with severe COVID-19 are more likely to have background comorbidities such as diabetes, hypertension, older age, airways disease, and obesity, risk factors frequently shared by several cardiovascular diseases. ${ }^{8}$

\section{Why COVID-19 became an issue for cardiovascular specialists? SARS-CoV-2- related myocardial injury and myocarditis}

Approximately $20-30 \%$ of hospitalized patients with COVID-19 have evidence of cardiac injury, as indicated by elevated levels of high-sensitivity troponins. ${ }^{9}$ The presence and magnitude of troponin elevation is associated with more severe disease and worse outcomes, even after adjusting for relevant risk factors. Myocardial injury portends a fatal outcome of COVID-19, while the prognosis of patients without myocardial injury, even with underlying cardiovascular disease, is more favorable. ${ }^{10}$

\section{Keywords}

Coronavirus-19; COVID-19; Syndrome Respiratory Acute Gravis; SARS-19; Betacoronavirus/complications; Pandemics; Cardiovascular Diseases/complications.

Mailing Address: Peter Libby •

Division of Cardiovascular Medicine, Department of Medicine, Brigham and Women's Hospital, Harvard Medical School, Boston, MA - USA plibby@bwh.harvard.edu

Manuscript received April 28, 2020, revised manuscript May 17, 2020 accepted May 30, 2021
The pathophysiology of SARS-CoV-2-induced myocardial injury remains a topic of active research. COVID-19 can unfavorably affect the balance between myocardial oxygen supply and demand, as with other overwhelming viral or bacterial infections (Figure 1). Fever, metabolic stress, sympathetic activation, and tachycardia increase the energy expenditure and oxygen consumption of the myocardium. ${ }^{11,12}$ This imbalance can provoke type 2 (or "demand" type) myocardial infarction. Hypoxia from respiratory impairment can favor the production of reactive oxygen species and oxidative stress, acidosis, mitochondrial damage, and cell death. ${ }^{11,13,14}$ Other mechanisms of myocardial injury during COVID-19 include ischemia from microvascular thrombi and toxic levels of cytokines. Cardiac damage due to direct SARS-CoV-2 infection of cardiac myocytes appears uncommon. ${ }^{14-16}$ Indeed, the pericytes, smooth-muscle like cells that surround microvessels, express high levels of the receptor for SARS-CoV-2, angiotensin converting enzyme 2 (ACE2), while cardiac myocytes themselves have few, if any, of these portals of entry used by the virus.

Patients with COVID-19-related myocardial injury may present cardiac dysfunction and arrhythmias. ${ }^{10}$ A single center study used advanced cardiovascular magnetic resonance (CMR) and found a high prevalence of myocardial edema and fibrosis in patients recovering from COVID-19, which was independent of preexisting conditions and of severity and overall course of the acute illness. ${ }^{17}$ A subsequent multicenter study also used CMR to follow myocardial injury. ${ }^{18}$ During recovery after severe COVID-19 with troponin elevation, patients still can present a myocarditis-like injury, but it is limited and without important functional consequence. Nearly half of the evaluated patients had an abnormal CMR imaging, with 3 patterns of injury: non-infarct, myocarditis-pattern injury $(27 \%)$, ischemic pathology $(22 \%)$, and non-ischemic non-specific scar (5\%). ${ }^{18}$

Although viral myocarditis appears uncommon in COVID-19, clinical conditions that may injure the myocardium include microvascular dysfunction and thrombosis, stress cardiomyopathy, and type 1 myocardial infarction. Heart failure in patients with COVID-19 may be precipitated by acute illness in patients with preexisting known or undiagnosed heart disease, acute hemodynamic stress, myocardial depression due to cytokines, or incident myocardial injury produced by the above-mentioned mechanisms. ${ }^{19}$

In the absence of obstructive epicardial coronary disease but evidence of myocardial injury (defined as positive troponin with or without wall motion abnormalities), physicians often consider the diagnosis of myocarditis as the underlying cause, using data such as clinical and imaging markers of myocyte injury.

DOI: https://doi.org/10.36660/abchf.20210001 


\section{Editorial}

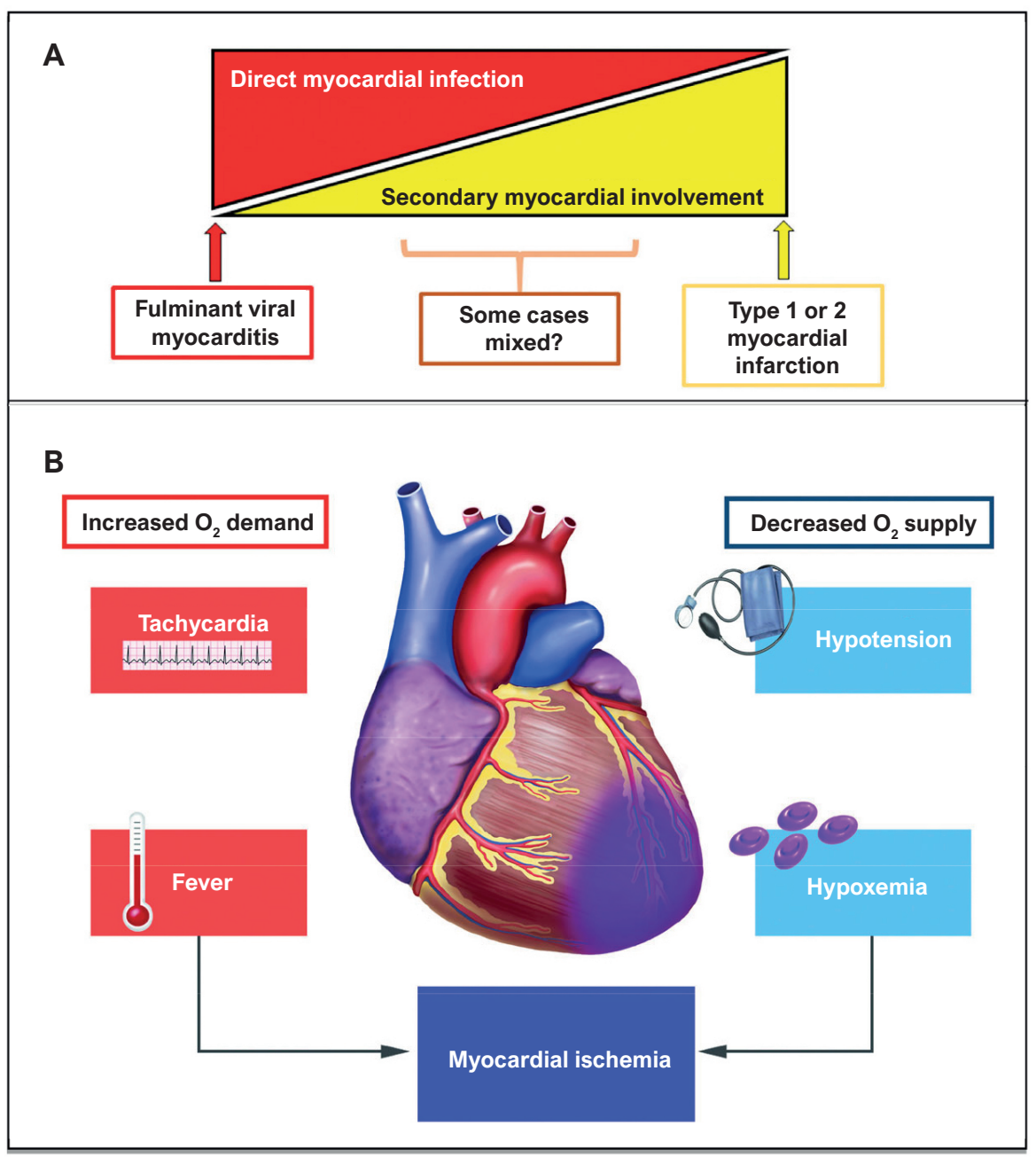

Figure 1 - A) This hypothetical diagram represents the spectrum of myocardial involvement in coronavirus disease 2019 (COVID-19). On the left, fulminant myocarditis due to direct myocardial infection. On the right, acute coronary syndrome developed from severe pre-existing lesions triggered by systemic inflammation from an active infection. B) Physiological changes associated with infection with severe acute respiratory syndrome coronavirus 2 (SARS-CoV-2) that alter the balance between myocardial oxygen supply and demand to favor myocardial ischemia. Adapted with permission from Libby P. The Heart in COVID-19: Primary Target or Secondary Bystander? JACC Basic Trans/ Sci. May 2020;5(5):537-542. doi:10.1016/j.jacbts.2020.04.001.114

Because the clinical presentation of myocarditis may vary, including vague or nonspecific symptoms such as fatigue, dyspnea, palpitations, and chest discomfort, the diagnosis of myocarditis in this setting is not straightforward. Indeed, most published cases of presumed myocarditis induced by COVID-19 infection were based on blood troponin levels or CMR, without biopsy confirmation. ${ }^{20,21}$ However, there have been few reported cases of histologically confirmed myocarditis, and viral myocarditis caused by SARS-CoV-2 has generally not been definitively demonstrated by histologic and viral genome analysis. ${ }^{19}$

\section{From a pulmonary perspective to vascular and thromboembolic consequences}

Initially conceived as a respiratory viral disease, the understanding of COVID-19 has broadened to encompass a heterogeneous and complex multi-organ condition. ${ }^{22,23}$ Emerging data indicates that COVID-19 patients have increased risk of broad systemic effects, including thrombosis, ${ }^{24-26}$ kidney failure, ${ }^{27,28}$ neurological events, ${ }^{29,30}$ and cardiovascular complications, such as heart failure $^{31,32}$ and cardiogenic shock. ${ }^{33}$ 
A retrospective study comparing COVID-19 survivors and non-survivors showed that non-survivors had significantly higher levels of D-dimer and fibrin degradation products, as well as longer prothrombin time and activated partial thromboplastin time at clinical presentation. ${ }^{34}$ These differences increased during serial measurements, with $71.4 \%$ of non-survivors meeting the International Society on Thrombosis and Hemostasis (ISTH) diagnostic criteria for overt disseminated intravascular coagulation. The coexistence of coagulation abnormalities, hyperfibrinolysis, and large-vessel thrombosis in patients with severe COVID-19 has been linked to multiple organ dysfunction syndromes. ${ }^{35-37}$

COVID-19-related endothelial activation, dubbed endothelitis by some, explains systemic microcirculatory impairment in different vascular beds and its clinical sequelae in patients with SARS-CoV-2 infection (Figure 2). ${ }^{38-40}$ In addition to pericytes, arteriolar smooth muscle cells can express ACE2, and might act as target cardiac cells of SARS-CoV-2. ${ }^{41,42}$ SARS-CoV-2 and SARS-CoV-1 share almost identical receptor-binding domains. Some clinical features of COVID-19 resemble those of other coronavirus infections, including SARS-CoV-1, which emerged in 2002, and MERS-CoV, which threatened a pandemic in 2012. ${ }^{43}$ However, the SARS-CoV-2 binding site has a more compact and stable conformation, with structural features that enhance affinity for ACE2 and a furin cleavage site that increases the ability to infect target cells. $^{43,44}$ The expression of ACE2 receptors on pericytes and microvascular smooth muscle cells, as well as findings of acute endothelitis in patients with COVID-19, provides a potential mechanism of direct viral injury through an infection-mediated vasculitis. ${ }^{38,41,45}$ Moreover, the presence of a furin cleavage site, which can be processed by near-ubiquitous furin-like proteases, sets SARS-CoV-2 apart from SARS-CoV-1 and other SARS-related coronaviridae that possess a monobasic cleavage site processed upon entry of target cells. ${ }^{46-48}$ Understanding the mechanisms and pathophysiology of SARS-CoV-2 infection and how it affects endothelial cells may provide useful insight on therapeutic and preventive strategies to avoid disease complications.

Recruitment of immune cells can cause widespread endothelial dysfunction associated with apoptosis. ${ }^{49,50}$ Pathologic data from patients with SARS-CoV-1 shows evidence of vasculitis with monocyte and lymphocyte infiltration, vascular endothelial cell injury, and stromal edema in the heart. ${ }^{51}$ Likewise, biopsies and post-mortem histological examination in patients with COVID-19 revealed lymphocytic endothelitis with apoptotic bodies and viral inclusion structures in multiple organs, including heart, lungs, kidneys, and intestine. ${ }^{7,38,52}$ The presence of viral elements within endothelial cells and accumulation of inflammatory cells, with evidence of endothelial and inflammatory cell death, suggests that SARS-CoV-2 infection yields endothelial activation in several organs, in addition to host's inflammatory response. ${ }^{53}$ Marked inflammation and endothelitis can also augment tissue factor expression, leading to a prothrombotic state. ${ }^{54-59}$ Analysis of pulmonary vessels in patients who died from COVID-19-related respiratory failure showed extensive thrombotic microangiopathy. ${ }^{52}$ Similar pathophysiology can apply to other organs affected by advanced COVID-19 as well.
Endothelial dysfunction resulting from infection and inflammation may lead to decreased coronary flow and destabilization of pre-existing atherosclerotic plaque, triggering a type 1 acute coronary event. ${ }^{60}$ Higher incidences of acute coronary syndromes, arrhythmias, heart failure-related events, and cardiovascular mortality observed during seasonal influenza outbreaks suggest a combination of systemic inflammation, vascular injury, and hypercoagulability. ${ }^{61,62}$ Additional reports of severe Kawasaki-like disease in children support the hypothesis of systemic hyperinflammation and widespread endothelial dysfunction in the pathogenesis of the most severe forms of COVID-19. ${ }^{63-65}$ The Kawasaki-like disease, also termed multisystem inflammatory syndrome in children, is characterized by persistent fever, gastrointestinal symptoms, rash, and conjunctivitis. ${ }^{63,64,66}$ Those children will typically present with 3-5 days of fever, followed by vasodilatory shock that is often refractory to volume resuscitation, requiring vasopressors and, occasionally, mechanical circulatory support.

Conceiving COVID-19 as a vascular disorder provides a rationale for endothelium-stabilizing therapies that can also impact viral replication, such as renin-angiotensin-aldosterone system inhibitors, ${ }^{38,67-70}$ statins, ${ }^{71-73}$ and anti-cytokine agents. ${ }^{74-76}$ These strategies could be particularly helpful in high-risk patients with preexisting endothelial dysfunction, such as those with hypertension, diabetes, obesity, and overt cardiovascular disease, all of which are associated with worse outcomes in COVID-19. Data available so far support the continuation of ACE inihibitor/angiotensin receptor blocker (ARB) and statins in patients taking them for pre-existing cardiovascular conditions. ${ }^{77}$ The blockade of interleukin (IL)-6, a cytokine produced by macrophages that induces a proinflammatory response and is often elevated in patients with COVID-19, has been recently studied, with contradictory results. ${ }^{78-83}$ We must await additional rigorously performed, properly powered, well-controlled, randomized trials before adopting or rejecting such therapies.

\section{The clinical clouds gather: the heart may not resist a cytokine storm.}

Massive cytokine release contributes to the most severe complications in COVID-19. ${ }^{53}$ Such an aggressive host inflammatory response commonly precipitates hemodynamic instability affecting all vessels, from veins to arteries of all calibers, and the microcirculation of many organs, as well as embolic phenomena, renal failure and shock. Acute heart failure with decrements of myocardial contractility can accompany this profound septic state. . $^{3,4,84}$

Intense inflammatory responses will involve overactivation of innate immunity, led by infections, or other stimuli, and will follow an uncontrolled rise in cytokines concentrations, causing collateral damage in tissues and multiple organs. ${ }^{85,86}$ The term "cytokine storm" first appeared in an article published in 1993 that describes the effects of graft-versushost disease. ${ }^{87}$ It gained notoriety after being used to describe the effects of the avian H5N1 virus infection in $2005 .^{88}$ Cytokine storm can complicate many infectious diseases, including SARS-CoV-1 and SARS-CoV- $2,{ }^{86,89}$ influenza virus, ${ }^{90}$ variola virus, ${ }^{91}$ cytomegalovirus, ${ }^{92}$ and group A streptococcus ${ }^{93}$ 


\section{Editorial}

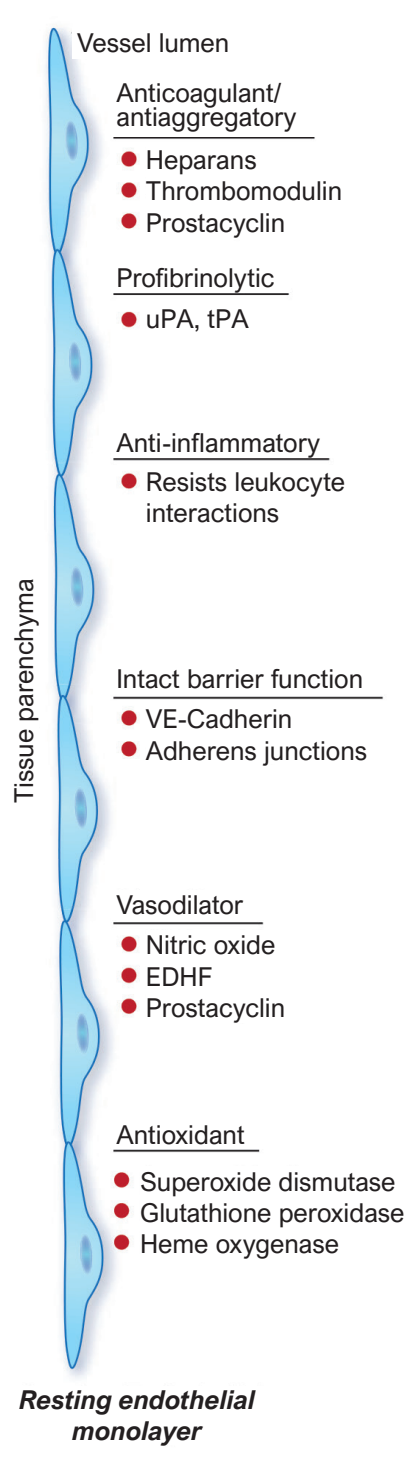

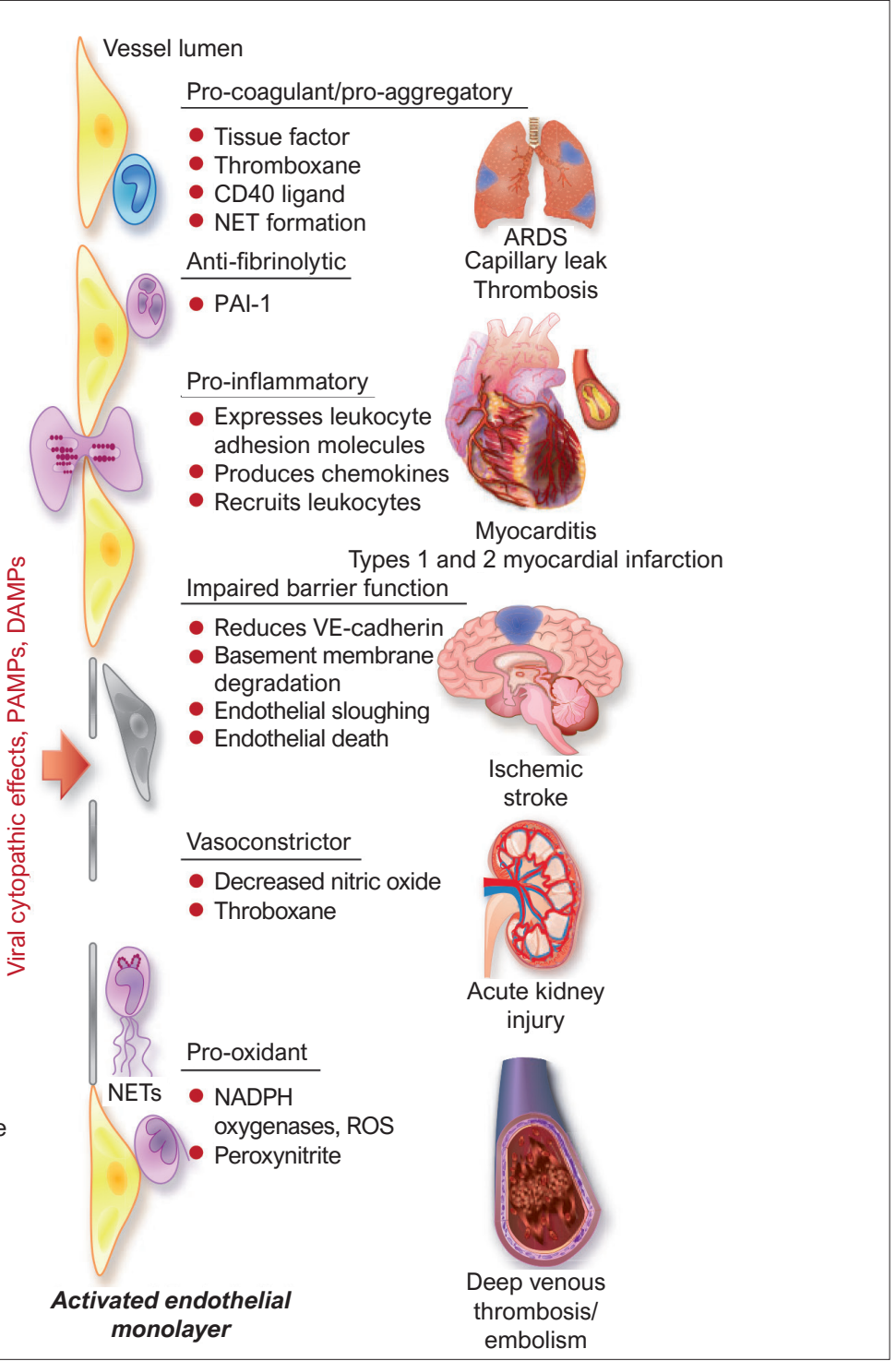

Figure 2 - The left side of the diagram depicts a resting endothelial monolayer with the endothelial cells of squamous morphology resting on an intact basement membrane. When the endothelial cells undergo the cytopathic effect of a viral infection such as that caused by severe acute respiratory syndrome coronavirus 2 (SARS-CoV-2), or encounter pathogen-associated molecular patterns (PAMPS) derived from viruses or bacteria, such as lipopolysaccharide, proinflammatory cytokines such as interleukin (IL)-1 or tumor necrosis factor (TNF), or damage-associated molecular patterns (DAMPS) derived from dead or dying cells, the endothelial cells become activated. The endothelial cells display more columnar morphology. They can express adhesion molecules that attract leucocytes and chemokines that direct their migration into the subendothelial space. Sloughing of endothelial cells uncovers the thrombogenic basement membrane. Adherent neutrophils can undergo formation of neutrophil extracellular traps (NETs) that provide an amplifier for endothelial damage mediated in part by IL-1a. Inflammatory activation of endothelial cells can disrupt VE-cadherin largely responsible for the integrity of the endothelial barrier function. Activated endothelial cells can also express matrix metalloproteinases that can degrade the basement membrane and further interrupt endothelial barrier function. In small vessels, such as those that embrace alveoli in the lung, this impaired barrier function can lead to capillary leak. These various disturbances in endothelial function, depicted in the middle part of the diagram, lead to end organ damage, including adult respiratory distress syndrome (ARDS) and thrombosis in the lungs, predispose to plaque rupture and thrombosis in coronary arteries, and affect the microvasculature leading to myocardial ischemia and damage. The thrombotic diathesis provoked by endothelial dysfunction can also predispose towards strokes. Microvascular and macrovascular injuries can potentiate acute renal failure. Hepatic dysfunction can also result from microvascular thrombosis among other mechanisms. Deep venous thrombosis can occur as endothelial dysfunction represents an important part of Virchow's triad, and sets the stage for pulmonary embolism. Thus, loss of the endothelial protective function and unleashing of the mechanisms depicted can lead to multiorgan system failure that characterizes the advanced stages of coronavirus disease 2019 (COVID-19). Adapted with permission from Libby P, Lüscher T. COVID-19 is, in the end, an endothelial disease. Eur Heart J. 09 2020;41(32):3038-3044. doi:10.1093/eurhearti/ehaa623. ${ }^{39}$ uPA: urokinase-type plasminogen activator; tPA: tissue-type plasminogen activator; EDHF: endothelium-derived hyperpolarizing factor; PAI-1: plasminogen activator inhibitor 1; NADPH: nicotinamide adenine dinucleotide phosphate; ROS: reactive oxygen species; MI: myocardial infarction. 
In the case of COVID-19, from the entrance of SARS-CoV-2 into a host cell, an active innate immune system responds with a cascade of processes, leading to the release of cytokines, such as interferons type I/III, tumor necrosis factor alpha (TNF- $\alpha$ ), IL-1 $\beta$, IL-18, and IL-6. Conversely, proinflammatory cytokines will alter endothelial cell homeostatic functions in a manner that can lead to thrombosis and local tissue injury. Within this inflammatory microenvironment, endothelial cells and invading leukocytes will produce IL-1, which can elicit the production of chemoattractant molecules, stimulating migration and penetration of more inflammatory cells into local tissues. ${ }^{94} \mathrm{IL}-1$ can induce its own gene expression, triggering an amplification loop that can fuel a cytokine storm (Figure 3). ${ }^{95-97}$ IL-1 can also enhance the gene expression of other proinflammatory cytokines, including TNF- $\alpha .{ }^{98} \mathrm{IL}-1$ potently sparks the production of another proinflammatory cytokine, IL-6.99,100 This induction of IL- 6 production by IL-1 provides another strong contributor for the amplification loop that will maintain the overwhelming cytokines production that characterizes a cytokine storm. IL-6 will act by boosting, in the liver, the synthesis of fibrinogen (precursor of clots), of plasminogen activator inhibitor 1 (PAl-1) (major inhibitor of fibrinolysis), and of C-reactive protein, a biomarker that is consistently elevated in COVID-19. ${ }^{101}$ IL-6 plays a major role in acute lung injury and serves as a biomarker to predict the severity of COVID-19. ${ }^{102-105}$ Consistently, high levels of other inflammatory biomarkers, as C-reactive protein, IL-2, TNF- $\alpha$, interferon-g, D-dimer, and ferritin, also correlate with severe manifestations and worse outcomes of patients with COVID-19. Lymphopenia and thrombocytopenia are frequent in this late phase of COVID-19.3,4,75,84,106,107 As components of the cellular immune response, natural killer (NK) cells and macrophages will undergo local activation, releasing cytokines to coordinate with activated $\mathrm{T}$ cells and other humoral responses in an attempt to resolve the infection rapidly. ${ }^{86}$ Severe COVID-19 can entail functional exhaustion of NK cells and CD8 + T lymphocytes, an evolution that favors virus persistence, macrophage activation, and further cytokine release. ${ }^{108,109}$ Antibody and cytotoxic T cell responses towards SARS-CoV can persist long after full recovery, with a moderate decline after one year from the onset of symptoms. ${ }^{110}$

Regarding cardiac dynamics, transient left ventricular dysfunction may occur during the acute phase of cytokine storm. A comparative echocardiographic study with SARS patients at the acute stage of infection and 30 days later showed a significantly higher left ventricular index of myocardial performance and a lower left ventricular ejection fraction, which characterized a subclinical diastolic impairment without systolic involvement at the acute phase. Furthermore, after 30 days, this impairment improved with clinical recovery. ${ }^{111}$ Patients who have recovered from cytokine storm syndrome may still bear long-lasting scars, such as pulmonary fibrosis, functional disability, and reduced quality of life. ${ }^{112}$ The long-term effect of myocardial injury sustained during acute COVID-19 will require careful attention in the coming years. Even in those who appear to recover fully from acute COVID-19, myocardial scarring could impair reserves required to withstand future insults. Fibrotic foci in the healed myocardium could nonetheless become substrates for reentrant arrhythmias as well as a long-term consequence of the acute SARS-CoV-2 infection.
At the level of the coronary arteries, the elevation of systemic cytokines can activate inflammatory cells resident in pre-existing atheroma and trigger a type 1 acute coronary syndrome due to plaque rupture. ${ }^{113}$ Cardiac ischemia can also arise from an imbalance between oxygen supply and demand. Even in the absence of epicardial atherosclerosis, the release of cytokines from a systemic or neighboring infection, such as pneumonitis, can activate the coronary microvascular endothelium and predispose to vasomotor abnormalities, augmented thrombosis, reduced fibrinolysis, increased leukocyte adhesion, and other aspects of dysfunction of heart microvessels. ${ }^{40,114}$

\section{Perspectives}

Is this pandemic ending or just beginning?

We are still learning about COVID-19 and new variants of SARS-CoV-2. Current evidence supports the use of remdesivir, glucocorticoids, prophylactic doses of anticoagulants, and anti-SARS-CoV-2 antibodies in certain hospitalized patients with COVID-19. We still need more evidence-based therapies for shortening the course of COVID-19 or reducing the need of mechanical ventilation or intensive care. The use of anticytokine agents might help to improve in more severe scenarios, in which there is dysfunction of biological systems and higher risk of fatalities. It is crucial to block an overwhelming wave of elevated cytokines, although we await the results of rigorous trials in this regard. ${ }^{74-76}$ There are few reports of reinfections following 50 days from recovery, ${ }^{115}$ and breakthrough infections can occur, albeit uncommonly, in those already vaccinated. Recovery from some symptoms, such as anosmia ${ }^{116}$ or fatigue, ${ }^{117}$ can also be incomplete.

Our current best approach to eradicate or, at least, control the SARS-CoV-2 threat is vaccination. There are many vaccines, based on different approaches, with results varying from reducing new cases to muting the advanced manifestations of COVID-19. The development of a variety of vaccines in rapid succession to confront the COVID-19 crisis represents a victory of medical science. We have reaped the benefits of decades of investment in basic research and in pharmaceutical development faced with this murderous pandemic. Since its recognition in December 2019, this pandemic has spurred many developments, strikingly altered most lives, disrupted daily routines, work, social gathering, exercising, with consequent challenges to both mental and physical health.

With the economic burden, strain on health systems, and urgent demand for vaccine, governments have struggled to accomplish the full vaccination of populations in a timely manner. We need to learn the durability of immunity conferred by the vaccines, and develop booster vaccinations that will prolong protection and broaden the spectrum of variants covered.

As a society, we must learn from this crisis to prepare ourselves to face future global health challenges in a more coherent and organized fashion. As professionals devoted to health care, we need to allow science rather than political considerations to lead our responses to public health disasters such as we have faced with COVID-19. To prepare for future outbreaks, investigators need to organize a priori to cooperate 


\section{Cytokine storm pathophysiology}

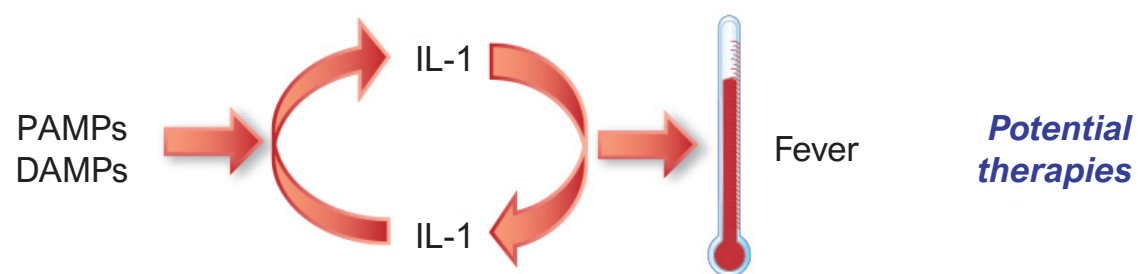

IL-1 autoinduction

IL-1 also induces TNF and CD154

Anti-IL-1 $\beta$ \& $\alpha$ Anti-TNF $\alpha$

NLRP3 inflammasome

(converts pro-IL-1 $\beta$ and IL-18 into active forms)
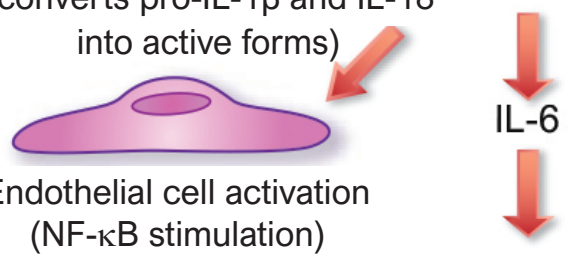

Inflammasome inhibitors, Colchicine

Endothelial cell activation (NF-kB stimulation)

Anti-IL-6

Statins

RAAS blockade

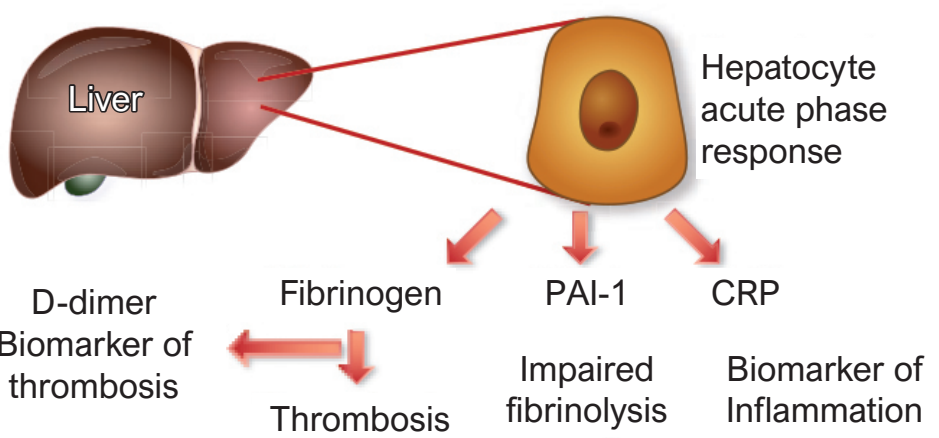

\section{Anti-coagulants}

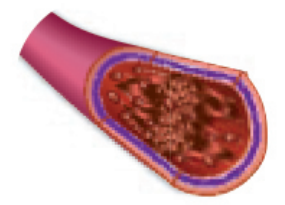

Arterial - eg, coronary, cerebral

Microvascular - eg, heart, kidney

Venous - DVT and PE

\section{Anti-platelet agents}

Thrombus

Figure 3 - Cytokine storm. Proinflammatory cytokines such as interleukin (IL)-1 and tumor necrosis factor alpha (TNF- $\alpha$ ) induce each other's gene expression, unleashing an amplification loop that sustains the cytokine storm. The endothelial cell is a key target of cytokines, as they induce action of a central proinflammatory transcriptional hub, nuclear factor kappa beta (NF-kB). IL-1 also causes substantial increases in production by endothelial and other cells of IL-6, the instigator of the hepatocyte acute phase response. The acute phase reactants include fibrinogen, the precursor of clot, and plasminogen activator inhibitor 1 (PAI-1), the major inhibitor of our endogenous fibrinolytic system. C-reactive protein (CRP), commonly elevated in coronavirus disease 2019 (COVID-19), provides a readily measured biomarker of inflammatory status. The alterations in the thrombotic/fibrinolytic balance due to the acute phase response promotes thrombosis in arteries, in the microvasculature, including that of organs such as the myocardium and kidney, and in veins, causing deep vein thrombosis (DVT) and predisposing towards pulmonary embolism (PE). Thus, the very same cytokines that elicit abnormal endothelial functions can unleash acute phase response, which, together with local endothelial dysfunction, can conspire to cause the clinical complications of COVID-19. The right side of this diagram aligns therapeutic agents that attack these mechanisms of the cytokine storm and may thus limit its devastating consequences. Adapted with permission from Libby P, Lüscher T. COVID-19 is, in the end, an endothelial disease. Eur Heart J. 09 2020;41(32):3038-3044. doi:10.1093/eurheartj/ehaa623. ${ }^{39}$ PAMPs: pathogen-associated molecular patterns; DAMPs: damage-associated molecular patterns; RAAS: renin-angiotensin-aldosterone system. 
internationally to perform randomized, blinded, controlled, and adequately powered trials, rather than a scattershot of smaller observational or poorly controlled studies. Scientific rigor is the only proper way forward. Interventions based on anecdote and unproven plausibility delay progress and thus represent a threat to public health. We must confront the glaring inequities this pandemic has aggravated among less privileged segments of society. We have a chance to learn lessons from this grave situation. It is our duty to do so, to prevent the inevitable future pandemics from taking such a deadly toll on our society in upending so many lives.

\section{Declaration of Competing Interest}

Dr. Peter Libby: Dr. Libby is an unpaid consultant to, or involved in clinical trials for Amgen, AstraZeneca, Baim Institute, Beren Therapeutics, Esperion Therapeutics,

\section{References}

1. Dong E, Du H, Gardner L. An interactive web-based dashboard to track COVID-19 in real time. Lancet Infect Dis. 05 2020;20(5):533-4.

2. Zhu N, Zhang D, Wang W, Li X, Yang B, Song J, et al. A Novel Coronavirus from Patients with Pneumonia in China, 2019. NEngl J Med. 02 2020;382(8):727-33.

3. Huang C, Wang Y, Li X, Ren L, Zhao J, Hu Y, et al. Clinical features of patients infected with 2019 novel coronavirus in Wuhan, China. Lancet. 02 2020;395(10223):497-506.

4. Zhou F, Yu T, Du R, Fan G, Liu Y, Liu Z, et al. Clinical course and risk factors for mortality of adult inpatients with COVID-19 in Wuhan, China: a retrospective cohort study. Lancet. 03 2020;395(10229):1054-62.

5. Lax SF, Skok K, Zechner P, Kessler HH, Kaufmann N, Koelblinger C, et al. Pulmonary Arterial Thrombosis in COVID-19 With Fatal Outcome: Results From a Prospective, Single-Center,Clinicopathologic Case Series. Ann Intern Med. May 2020;173(5):350-61.

6. Wölfel R, Corman VM, Guggemos W, Seilmaier M, Zange S, Muller MA, et al Virological assessment of hospitalized patients with COVID-2019. Nature. 05 2020;581(7809):465-9

7. Xu Z, Shi L, Wang Y, Zhang J, Huang L, Zhang C, et al. Pathological findings of COVID-19 associated with acute respiratory distress syndrome. Lancet Respir Med. 04 2020;8(4):420-2.

8. Van Linthout S, Klingel K, Tschöpe C. SARS-CoV-2-related myocarditis-like syndromes Shakespeare's question: what's in a name? Eur J Heart Fail. 06 2020;22(6):922-5

9. Lala A, Johnson KW, Januzzi JL, Russak AJ, Paranjpe I, Richter F, et al. Prevalence and Impact of Myocardial Injury in Patients Hospitalized With COVID-19 Infection. J Am Coll Cardiol. 08 2020;76(5):533-46.

10. Guo T, Fan Y, Chen M, Wu X, Zhang L, He T, et al. Cardiovascular Implications of Fatal Outcomes of Patients With Coronavirus Disease 2019 (COVID-19). JAMA Cardiol. 07 2020;5(7):811-8.

11. Violi F, Cangemi R, Falcone M, Taliani G, Pieralli F, Vannucchi V, et al Cardiovascular Complications and Short-term Mortality Risk in CommunityAcquired Pneumonia. Clin Infect Dis. Jun 2017;64(11):1486-93.

12. Tomasoni $D$, Italia $L$, Adamo M, Inciardi RM, Lombardi CM, Solomon S, et al. COVID 19 and heart failure: from infection to inflammation and angiotensin II stimulation. Searching for evidence from a new disease. Eur J Heart Fail. May 2020; 22(6):957-66.

13. Wang D, Hu B, Hu C, Zhu F, Liu X, Zhang J, et al. Clinical Characteristics of 138 Hospitalized Patients With 2019 Novel Coronavirus-Infected Pneumonia in Wuhan, China. JAMA. 03 2020;323(11):1061-9.
Genentech, Kancera, Kowa Pharmaceuticals, Medimmune, Merck, Norvo Nordisk, Merck, Novartis, Pfizer, SanofiRegeneron. Dr. Libby is a member of scientific advisory board for Amgen, Corvidia Therapeutics, DalCor Pharmaceuticals, Kowa Pharmaceuticals, Olatec Therapeutics, Medimmune, Novartis, and XBiotech, Inc. Dr. Libby's laboratory has received research funding in the last 2 years from Novartis. Dr. Libby is on the Board of Directors of XBiotech, Inc. Dr. Libby has a financial interest in Xbiotech, a company developing therapeutic human antibodies. Dr. Libby's interests were reviewed and are managed by Brigham and Women's Hospital and Partners HealthCare in accordance with their conflict of interest policies. Dr. Libby receives funding support from the National Heart, Lung, and Blood Institute (1R01HL134892), the American Heart Association (18CSA34080399), the RRM Charitable Fund, and the Simard Fund.
14. Lippi G, Lavie CJ, Sanchis-Gomar F. Cardiac troponin I in patients with coronavirus disease 2019 (COVID-19): Evidence from a meta-analysis. Prog Cardiovasc Dis. Mar 2020; 63(3):390-1.

15. Giustino G, Croft LB, Stefanini GG, Bragato R, Silbiger JJ, Vicenzi M, et al Characterization of Myocardial Injury in Patients With COVID-19. J Am Coll Cardiol. 11 2020;76(18):2043-55

16. Bavishi C, Bonow RO, Trivedi V, Abbott JD, Messerli FH, Bhatt DL. Special Article - Acute myocardial injury in patients hospitalized with COVID-19 infection: A review. Prog Cardiovasc Dis. 2020 Sep - Oct 2020;63(5):682-9.

17. Puntmann VO, Carerj ML, Wieters I, Fahim M, Arendt C, Hoffman I, et al. Outcomes of Cardiovascular Magnetic Resonance Imaging in Patients Recently Recovered From Coronavirus Disease 2019 (COVID-19). JAMA Cardiol. Nov 2020;5(11):1265-73.

18. Kotecha T, KnightDS, RazviY, Kumar K, Vimalesvaran, Thornton G, etal. Patterns of myocardial injury in recovered troponin-positive COVID-19 patients assessed by cardiovascular magnetic resonance. Eur Heart J. Feb 2021;42(19):1866-78

19. Kawakami R, Sakamoto A, Kawai K, Gianatti A, Pellegrini D, Nasr A, et al. Pathological Evidence for SARS-CoV-2 as a Cause of Myocarditis: JACC Review Topic of the Week. J Am Coll Cardiol. 01 2021;77(3):314-25.

20. ZengJH, Liu YX, Yuan J, Wang FX, Wu WB, Li JX, et al. First case of COVID-19 complicated with fulminant myocarditis: a case report and insights. Infection. Apr 2020;48(5):773-7.

21. Sala S, Peretto G, Gramegna M, Palmisano A, Villatore A, Vignale D, et al. Acute myocarditis presenting as a reverse Tako-Tsubo syndrome in a patient with SARS-CoV-2 respiratory infection. Eur Heart J. 05 2020;41(19):1861-2.

22. Bryce C, Grimes Z, Pujadas E, Ahuja S, Beasley MB, Albrecht R, et al Pathophysiology of SARS-CoV-2: targeting of endothelial cells renders a complex disease with thrombotic microangiopathy and aberrant immune response. The Mount Sinai COVID-19 autopsy experience. medRxiv. 2020:2020.05.18.20099960.

23. LangJP, Wang X, Moura FA, Siddiqi HK, Morrow DA, Bohula EA. Acurrent review of COVID-19 for the cardiovascular specialist. Am HeartJ. May 2020;226:29-44.

24. Bikdeli B, Madhavan MV, Jimenez D, Chuich T, Dreyfus I, Driggin E, et al COVID-19 and Thrombotic or Thromboembolic Disease: Implications for Prevention, Antithrombotic Therapy, and Follow-up. J Am Coll Cardiol. Apr 2020;75(23):2950-73.

25. Klok FA, Kruip MJ, van der Meer NJ, Arbous MS, Gommers DA, Kant KM, et al. Incidence of thrombotic complications in critically ill ICU patients with COVID-19. Thromb Res. 07 2020;191:145-7. 
26. Poissy J, Goutay J, Caplan M, Parmentier E, Duburcq T, Lassalle F, et al. Pulmonary Embolism in COVID-19 Patients: Awareness of an Increased Prevalence. Circulation. Apr 2020; 142(2):184-6.

27. Durvasula R, Wellington T, McNamara E, Watnick S. COVID-19 and Kidney Failure in the Acute Care Setting: Our Experience From Seattle. Am J Kidney Dis. Apr 2020; 76(1):4-6.

28. Ronco C, Reis T. Kidney involvement in COVID-19 and rationale for extracorporeal therapies. Nat Rev Nephrol. 06 2020;16(6):308-10.

29. Aggarwal G, Lippi G, Henry B. Cerebrovascular disease is associated with an increased disease severity in patients with Coronavirus Disease 2019 (COVID-19): A pooled analysis of published literature. Int J Stroke. 06 2020;15(4):385-9.

30. Mao L, Jin H, Wang M, Hu Y, Chen S, He Q, et al. Neurologic Manifestations of Hospitalized Patients With Coronavirus Disease 2019 in Wuhan, China. JAMA Neurol. Apr 2020;77(6):683-90.

31. Dong N, Cai J, Zhou Y, Liu J, Li F. End-Stage Heart Failure With COVID-19: Strong Evidence of Myocardial Injury by 2019-nCoV. JACC Heart Fail. 06 2020;8(6):515-7.

32. Mehra MR, Ruschitzka F. COVID-19 Illness and Heart Failure: A Missing Link? JACC Heart Fail. 06 2020;8(6):512-4.

33. Tavazzi G, Pellegrini C, Maurelli M, Belliato M, Sciutti F, Bottazzi A, et al. Myocardial localization of coronavirus in COVID-19 cardiogenic shock. Eur J Heart Fail. 05 2020;22(5):911-5.

34. Tang N, Li D, Wang X, Sun Z. Abnormal coagulation parameters are associated with poor prognosis in patients with novel coronavirus pneumonia. J Thromb Haemost. 04 2020;18(4):844-7.

35. Tang N, Bai H, Chen X, Gong J, Li D, Sun Z. Anticoagulant treatment is associated with decreased mortality in severe coronavirus disease 2019 patients with coagulopathy. J Thromb Haemost. 05 2020;18(5):1094-9.

36. Zhu J, Ji P, Pang J, Zhong Z, Li H, He C, et al. Clinical characteristics of 3,062 COVID-19 patients: a meta-analysis. J Med Virol. Apr 2020;92(10):1902-14.

37. Porfidia A, Pola R. Venous thromboembolism in COVID-19 patients. J Thromb Haemost. 06 2020;18(6):1516-7.

38. Varga Z, Flammer AJ, Steiger P, Haberecker M, Andermatt R, Zinkernagel AS, et al. Endothelial cell infection and endotheliitis in COVID-19. Lancet. 05 2020;395(10234):1417-8.

39. Libby P, Lüscher T. COVID-19 is, in the end, an endothelial disease. Eur Heart J. 09 2020;41(32):3038-44.

40. Siddiqi HK, Libby P, Ridker PM. COVID-19 - A vascular disease. Trends Cardiovasc Med. 01 2021;31(1):1-5.

41. Chen L, Li X, Chen M, Feng Y, Xiong C. The ACE2 expression in human heart indicates new potential mechanism of heart injury among patients infected with SARS-CoV-2. Cardiovasc Res. 05 2020;116(6):1097-100.

42. He L, Mäe MA, Muhl L, Sun Y, Nahar K, Liébanas EV, et al. Pericyte-specific vascular expression of SARS-CoV-2 receptor ACE2 - implications for microvascular inflammation and hypercoagulopathy in COVID-19. bioRxiv. 2020:2020.05.11.088500.

43. Shang J, Ye G, Shi K, Wan Y, Luo C, Aihara H, et al. Structural basis of receptor recognition by SARS-CoV-2. Nature. 05 2020;581(7807):221-4.

44. Yan R, Zhang Y, Li Y, Xia L, Guo Y, Zhou Q. Structural basis for the recognition of SARS-CoV-2 by full-length human ACE2. Science. 03 2020;367(6485):1444-8.

45. Guzik TJ, Mohiddin SA, Dimarco A, Patel V, Sawatis K, Marelli-Berg FM, etal. COVID-19 and the cardiovascular system: implications for risk assessment, diagnosis, and treatment options. Cardiovasc Res. Apr 2020;116(10):1666-87

46. Coutard B, Valle C, de Lamballerie X, Canard B, Seidah NG, Decroly E. The spike glycoprotein of the new coronavirus 2019-nCoV contains a furin-like cleavage site absent in CoV of the same clade. Antiviral Res. 04 2020;176:104742
47. Walls AC, Park YJ, Tortorici MA, Wall A, McGuire AT, Veesler D. Structure, Function, and Antigenicity of the SARS-CoV-2 Spike Glycoprotein. Cell. 04 2020;181(2):281-92.e6.

48. Liu T, Luo S, Libby P, Shi GP. Cathepsin L-selective inhibitors: A potentially promising treatment for COVID-19 patients. Pharmacol Ther. 09 2020;213:107587.

49. Pagnoux C, Cohen P, Guillevin L. Vasculitides secondary to infections. Clin Exp Rheumatol. 2006 Mar-Apr 2006;24(2 Suppl 41):S71-81.

50. Guillevin L. Virus-induced systemic vasculitides: new therapeutic approaches. Clin Dev Immunol. 2004 Sep-Dec 2004;11(3-4):227-31 .

51. Ding Y, Wang H, Shen H, Li Z, Geng J, Han H, et al. The clinical pathology of severe acute respiratory syndrome (SARS): a report from China.J Pathol. Jul 2003;200(3):282-9.

52. Ackermann M, Verleden SE, Kuehnel M, Haverich A, Welte T, Laenger F, et al. Pulmonary Vascular Endothelialitis, Thrombosis, and Angiogenesis in Covid-19. N Engl J Med. May 2020; 383(2):120-8.

53. Siddiqi HK, Mehra MR. COVID-19 illness in native and immunosuppressed states: A clinical-therapeutic staging proposal. J Heart Lung Transplant. 05 2020;39(5):405-7.

54. Nakamura S, Imamura T, Okamoto K. Tissue factor in neutrophils: yes. J Thromb Haemost. Feb 2004;2(2):214-7.

55. van der Poll T, Büller HR, ten Cate H, Wortel CH, Bauer KA, Deventer SJ, et al. Activation of coagulation after administration of tumor necrosis factor to normal subjects. N Engl J Med. Jun 1990;322(23):1622-7.

56. de Jonge E, Friederich PW, Vlasuk GP, Rote W, Vroom MB, Levi M, et al Activation of coagulation by administration of recombinant factor VIla elicits interleukin 6 (IL-6) and IL-8 release in healthy human subjects. Clin Diagn Lab Immunol. May 2003;10(3):495-7.

57. Franco RF, de Jonge E, Dekkers PE, Timmerman JJ, Spek CA, van Deventer SJ, et al. The in vivo kinetics of tissue factor messenger RNA expression during human endotoxemia: relationship with activation of coagulation. Blood. Jul 2000;96(2):554-9.

58. Hendren NS, Drazner MH, Bozkurt B, Cooper LT. Description and Proposed Management of the Acute COVID-19 Cardiovascular Syndrome. Circulation. Jun 2020;141(23):1903-14

59. Ding YQ, Wang HJ, Shen H, Li Z, Geng J, Han H, et al. [Study on etiology and pathology of severe acute respiratory syndrome]. Zhonghua Bing Li Xue Za Zhi. Jun 2003;32(3):195-200.

60. Vallance P, Collier J, Bhagat K. Infection, inflammation, and infarction: does acute endothelial dysfunction provide a link? Lancet. May 1997:349(9062):1391-2.

61. Nguyen JL, Yang W, Ito K, Matte TD, Shaman J, Kinney PL. Seasonal Influenza Infections and Cardiovascular Disease Mortality. JAMA Cardiol. 06 2016;1(3):274-81.

62. Madjid M, Safavi-Naeini P, Solomon SD, Vardeny O. Potential Effects of Coronaviruses on the Cardiovascular System: A Review. JAMA Cardiol. Mar 2020; 5(7):831-40.

63. Riphagen S, Gomez X, Gonzalez-Martinez C, Wilkinson N, Theocharis P. Hyperinflammatory shock in children during COVID-19 pandemic. Lancet. 05 2020;395(10237):1607-8.

64. Licciardi F, Pruccoli G, Denina M, Parodi E, Taglietto M, Rosati S, etal. SARSCoV-2-Induced Kawasaki-Like Hyperinflammatory Syndrome: A Novel COVID Phenotype in Children. Pediatrics. May 2020; 146(2):e20201711.

65. Viner RM, Whittaker E. Kawasaki-like disease: emerging complication during the COVID-19 pandemic. Lancet. 06 2020;395(10239):1741-3.

66. Toubiana J, Poirault C, Corsia A, Bajolle F, Fourgeaud J, Angoulvant F, et al. Kawasaki-like multisystem inflammatory syndrome in children during the covid-19 pandemic in Paris, France: prospective observational study. BMJ. 06 2020;369:m2094. 
67. Jarcho JA, Ingelfinger JR, Hamel MB, D'Agostino RB, Harrington DP. Inhibitors of the Renin-Angiotensin-Aldosterone System and Covid-19. N Engl/ Med. May 2020; 382(25):2462-4.

68. Vaduganathan M, Vardeny O, Michel T, McMurray JJ, Pfeffer MA, Solomon SD. Renin-Angiotensin-Aldosterone System Inhibitors in Patients with Covid-19. N Engl J Med. 04 2020;382(17):1653-9.

69. Reynolds HR, Adhikari S, Pulgarin C, Troxel AB, Iturrate E, Johnson SB, et al. Renin-Angiotensin-Aldosterone System Inhibitors and Risk of Covid-19. N Eng/ J Med. May 2020; 382(25):2441-8.

70. Mancia G, Rea F, Ludergnani M, Apolone G, Corrao G. Renin-AngiotensinAldosterone System Blockers and the Risk of Covid-19. N Engl J Med. May 2020; 382(25):2431-40

71. Lee KC, Sewa DW, Phua GC. Potential role of statins in COVID-19. Int J Infect Dis. Jun 2020; 96:615-7.

72. Castiglione V, Chiriacò M, Emdin M, Taddei S, Vergaro G. Statin therapy in COVID-19 infection. Eur Heart / Cardiovasc Pharmacother. Apr 2020; 6(4):258-9.

73. Fedson DS. Treating influenza with statins and other immunomodulatory agents. Antiviral Res. Sep 2013;99(3):417-35.

74. Kang S, Tanaka T, Narazaki M, Kishimoto T. Targeting Interleukin-6 Signaling in Clinic. Immunity. 04 2019;50(4):1007-23.

75. Agarwal S, June $\mathrm{CH}$. Harnessing CAR T-cell Insights to Develop Treatments for Hyperinflammatory Responses in Patients with COVID-19. Cancer Discov. 06 2020;10(6):775-8.

76. Xu X, Han M, Li T, Sun W, Wang D, Fu B, et al. Effective treatment of severe COVID-19 patients with tocilizumab. Proc Natl Acad Sci U S A. 05 2020;117(20):10970-5.

77. Lopes RD, Macedo AV, Silva PG, Moll-Bernardes R, Santos TM, Mazza L, et al. Effect of Discontinuing vs Continuing Angiotensin-Converting Enzyme Inhibitors and Angiotensin II Receptor Blockers on Days Alive and Out of the Hospital in Patients Admitted With COVID-19: A Randomized Clinical Trial. JAMA. 01 2021;325(3):254-64.

78. Rubin EJ, Longo DL, Baden LR. Interleukin-6 Receptor Inhibition in Covid-19 - Cooling the Inflammatory Soup. N Eng/J Med. 04 2021;384(16):1564-5.

79. Hermine O, Mariette X, Tharaux PL, Rigon MR, Porcher R, Ravaud P. Effect of Tocilizumab vs Usual Care in Adults Hospitalized With COVID-19 and Moderate or Severe Pneumonia: A Randomized Clinical Trial. JAMA Intern Med. 01 2021;181(1):32-40.

80. Salvarani C, Dolci G, Massari M, Merlo DF, Cavuto S, Savoldi L, etal. Effect of Tocilizumab vs Standard Care on Clinical Worsening in Patients Hospitalized With COVID-19 Pneumonia: A Randomized Clinical Trial. JAMA Intern Med. 01 2021;181(1):24-31.

81. Gordon AC, Mouncey PR, Al-Beidh F, Rowan KM, Nichol AD, Arabi YM, et al. Interleukin-6 Receptor Antagonists in Critically III Patients with Covid-19. N Engl J Med. 04 2021;384(16):1491-502.

82. Salama C, Han J, Yau L, Reiss WG, Kramer B, Neidhart J, et al. Tocilizumab in Patients Hospitalized with Covid-19 Pneumonia. N Engl J Med. 01 2021;384(1):20-30

83. Rosas IO, Bräu N, Waters M, Go RC, Hunter BD, Bhagani S, et al. Tocilizumab in Hospitalized Patients with Severe Covid-19 Pneumonia. N Engl J Med. 04 2021;384(16):1503-16

84. Shi S, Qin M, Shen B, Cai Y, Liu T, Yang F, et al. Association of Cardiac Injury With Mortality in Hospitalized Patients With COVID-19 in Wuhan, China. JAMA Cardiol. Mar 2020; 5(7):802-10.

85. Tisoncik JR, Korth MJ, Simmons CP, Farrar J, Martin TR, Katze MG. Into the eye of the cytokine storm. Microbiol Mol Biol Rev. Mar 2012;76(1):16-32.

86. Wang J, Jiang M, Chen X, Montaner LJ. Cytokine storm and leukocyte changes in mild versus severe SARS-CoV-2 infection: Review of 3939 COVID-19 patients in China and emerging pathogenesis and therapy concepts. J Leukoc Biol. Jun 2020; 108(1):17-41
87. Ferrara JL, Abhyankar S, Gilliland DG. Cytokine storm of graft-versushost disease: a critical effector role for interleukin-1. Transplant Proc. Feb 1993;25(1 Pt 2):1216-7.

88. Yuen KY, Wong SS. Human infection by avian influenza A H5N1. Hong Kong Med J. Jun 2005;11(3):189-99.

89. Huang KJ, Su IJ, Theron M, Wu YC, Lai SK, Liu CC, et al. An interferon-gammarelated cytokine storm in SARS patients. J Med Virol. Feb 2005;75(2):185-94.

90. Liu Q, Zhou YH, Yang ZQ. The cytokine storm of severe influenza and development of immunomodulatory therapy. Cell Mol Immunol. Jan 2016;13(1):3-10

91. Jahrling PB, Hensley LE, Martinez MJ, Leduc JW, Rubins KH, Relman $\mathrm{DA}$, et al. Exploring the potential of variola virus infection of cynomolgus macaques as a model for human smallpox. Proc Natl Acad Sci U S A. Oct 2004:101(42):15196-200.

92. Barry SM, Johnson MA, Janossy G. Cytopathology or immunopathology? The puzzle of cytomegalovirus pneumonitis revisited. Bone Marrow Transplant. Sep 2000;26(6):591-7.

93. Bisno AL, Brito MO, Collins CM. Molecular basis of group A streptococcal virulence. Lancet Infect Dis. Apr 2003;3(4):191-200.

94. Wang JM, Sica A, Peri G, Walter S, Padura IM, Libby P, et al. Expression of monocyte chemotactic protein and interleukin-8 by cytokine-activated human vascular smooth muscle cells. Arterioscler Thromb. 1991 Sep-Oct 1991:11(5):1166-74

95. Dinarello CA, Ikejima T, Warner SJ, Orencole SF, Lonnemann G, Cannon G, et al. Interleukin 1 induces interleukin 1. I. Induction of circulating interleukin 1 in rabbits in vivo and in human mononuclear cells in vitro. $J$ Immunol. Sep 1987;139(6):1902-10.

96. Warner SJ, Auger KR, Libby P. Human interleukin 1 induces interleukin 1 gene expression in human vascular smooth muscle cells. J Exp Med. May 1987:165(5):1316-31.

97. Warner SJ, Auger KR, Libby P. Interleukin 1 induces interleukin 1. II. Recombinant human interleukin 1 induces interleukin 1 production by adult human vascular endothelial cells. J Immunol. Sep 1987;139(6):1911-7.

98. Warner SJ, Libby P. Human vascular smooth muscle cells. Target for and source of tumor necrosis factor. J Immunol. Jan 1989;142(1):100-9.

99. Loppnow H, Libby P.Adult human vascular endothelial cells expressthe IL6gene differentially in response to LPS or IL1.Cell Immunol. Sep 1989;122(2):493-503.

100. Loppnow H, Libby P. Proliferating or interleukin 1-activated human vascular smooth muscle cells secrete copious interleukin 6. J Clin Invest. Mar 1990;85(3):731-8.

101. Wright FL, Vogler TO, Moore EE, Moore HB, Wohlauer MV, Urban S, et al. Fibrinolysis Shutdown Correlation with Thromboembolic Events in Severe COVID-19 Infection. J Am Coll Surg. 08 2020;231(2):193-203.e1.

102. Aziz M, Fatima R, Assaly R. Elevated interleukin-6 and severe COVID-19: A meta-analysis. J Med Virol. Apr 2020; 92(11):2283-5.

103. Ulhaq ZS, Soraya GV. Interleukin-6 as a potential biomarker of COVID-19 progression. Med Mal Infect. 06 2020;50(4):382-3.

104. Magro G. SARS-CoV-2 and COVID-19: is interleukin-6 (IL-6) the 'culprit lesion' of ARDS onset? What is there besides Tocilizumab? SGP130Fc. Cytokine X. May 2020;2(2):100029.

105. Liu B, Li M, Zhou Z, Guan X, Xiang Y. Can we use interleukin-6 (IL-6) blockade for coronavirus disease 2019 (COVID-19)-induced cytokine release syndrome (CRS)? J Autoimmun. 07 2020;111:102452.

106. Qin C, Zhou L, Hu Z, Zhang S, Yang S, Tao Y, et al. Dysregulation of immune response in patients with COVID-19 in Wuhan, China. Clin Infect Dis. Mar 2020; 71(15):762-8.

107. Mehta P, McAuley DF, Brown M, Sanchez E, Tattersall RS, Manson JJ, et al. COVID-19: consider cytokine storm syndromes and immunosuppression. Lancet. 03 2020;395(10229):1033-4 


\section{Editorial}

108. Zheng M, Gao Y, Wang G, Song G, Liu S, Sun D, et al. Functional exhaustion of antiviral lymphocytes in COVID-19 patients. Cell Mol Immunol. 05 2020;17(5):533-5.

109. Diao B, Wang C, Tan Y, Chen X, Liu Y, Ning L, et al. Reduction and Functional Exhaustion of T Cells in Patients With Coronavirus Disease 2019 (COVID-19). Front Immunol. 2020;11:827.

110. Li T, Xie J, He Y, Fan H, Baril L, Qiu Z, et al. Long-term persistence of robust antibody and cytotoxic $T$ cell responses in recovered patients infected with SARS coronavirus. PLoS One. Dec 2006;1(1):e24.

111.Li SS, Cheng CW, Fu CL, Chan Y, Lee M, Chan JW, et al. Left ventricular performance in patients with severe acute respiratory syndrome: a 30-day echocardiographic follow-up study. Circulation. Oct 2003;108(15):1798-803.

112. Cui N, Zou X, Xu L. Preliminary CT findings of coronavirus disease 2019 (COVID-19). Clin Imaging. May 2020;65:124-32.
113.Madjid M, Vela D, Khalili-Tabrizi H, Casscells SW, Litovsky S. Systemic infections cause exaggerated local inflammation in atherosclerotic coronary arteries: clues to the triggering effect of acute infections on acute coronary syndromes. Tex Heart Inst J. 2007;34(1):11-8.

114. Libby P. The Heart in COVID-19: Primary Target or Secondary Bystander? JACC Basic Transl Sci. May 2020;5(5):537-42.

115. Santos LA, Gois Filho PG, Silva AM, Santos JV, Santos DS, Aquino MM, et al. RecurrentCOVID-19 including evidence of reinfection and enhanced severity in thirty Brazilian healthcare workers. J Infect. Feb 2021;82(3):399-406.

116. Lechien JR, Chiesa-Estomba CM, Beckers E, Mustin V, Ducarme M, Journe F, et al. Prevalence and 6-month recovery of olfactory dysfunction: a multicentre study of 1363 COVID-19 patients. I Intern Med. Jan 2021.

117. Willi S, Lüthold R, Hunt A, Hanggi NV, Sejdiu D, Scaff C, et al. COVID-19 Sequelae in adults aged less than 50 years: A Systematic Review. Travel Med Infect Dis. Feb 2021;40:101995. 